\title{
Evidence and theory based promotion of health-enhancing physical activity
}

\author{
Seppo Miilunpalo* \\ UKK Institute for Health Promotion Research, FIN-33500 Tampere, Finland
}

\begin{abstract}
Physical activity appears to improve health-related quality of life by enhancing psychological well being and by improving physical functioning, particularly in persons compromised by poor health. Health enhancing physical activity (HEPA) can in addition to, and instead of, structured and planned exercise and sports comprise other forms of physical activity, such as occupational activities, lifestyle activities and recreational activities. However, wide-range and long-term population strategies are needed for the promotion of physical activity in each of the categories of HEPA. It is necessary to create realistic opportunities for different population groups and individuals. The theoretical knowledge of the determinants of the target behaviour has to be translated to a practical form. On the basis of available empirical studies, the Predisposing, Enabling and Reinforcing factors in the PRECEDEPROCEED model for health promotion, are all relevant and important for the adoption and maintenance of physical activity. In the end, promotional activities are needed where people live and work, i.e. at local level.
\end{abstract}

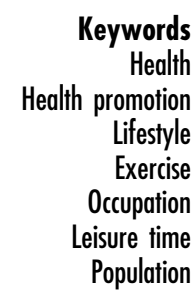

\section{Physical activity and health}

Scientific knowledge of the health consequences of physical activity and inactivity has substantially increased during the last 20 years. Current knowledge is based on a wide range of evidence. Above all, it is based on carefully designed and conducted prospective and retrospective epidemiological studies, as wells as on short term and long term randomised controlled trials. It is also based on other experimental studies, and on meta-analyses of the available research data ${ }^{1-3}$.

On the basis of the accumulated research data, in childhood adequate amounts of physical activity promote the healthy development and growth of the child, e.g. weight-bearing physical activity is essential for the normal skeletal development during childhood and adolescence and for achieving optimal peak bone mass. In all ages regular physical activity is necessary for maintaining muscle strength, joint structure and function, and it helps to keep appropriate body weight.

Especially in older adults physical activity and training maintain the functional ability and preserve independent living status. Among middle-aged and older adults regular physical activity decreases the risk or delays the development of many chronic cardiovascular and metabolic diseases and the risk of premature death. Regular moderate physical activity is also beneficial in the treatment and rehabilitation of many diseases and disabilities, and it may relieve symptoms of depression and anxiety and improve mood ${ }^{1-3}$.

Strenuous exercise and sports are related to increased risk of musculoskeletal injuries. In recreational and fitness-related activities these are believed to be mostly preventable by gradually working up to a desired level of activity and by avoiding excessive amounts of activity. Among older individuals the risk of serious cardiovascular events is increased.

In population studies the net effect of regular physical activity is to lower the risk of cardiovascular disease mortality, and on an individual level the risk can be reduced by physical examination and by avoiding too strenuous exercise. As a conclusion, physical activity appears to improve health-related quality of life by enhancing psychological well being and by improving physical functioning, particularly in persons compromised by poor health ${ }^{1-3}$.

\section{Need for the promotion of physical activity}

The promotion of regular moderate physical activity has been recommended in the recent statements of several expert committees ${ }^{2,4,5}$. Ordinary people can obtain significant health benefits by including a moderate amount of physical activity on most if not all days of the week. Therefore sedentary adults are encouraged to accumulate at least 30 minutes of moderate intensity 
physical activity, such as brisk walking, in their daily life. However, additional health benefits can be gained through greater amounts in terms of longer duration or higher intensity of the weekly physical activity.

The current recommendations are based on a new synthesis of the accumulated evidence. Major health benefits can be obtained with less intensive exercise than recommended by the earlier fitness guidelines ${ }^{4,6}$, and at population level most health benefits would be available by promoting regular moderate physical activity among the least active population groups than increasing the amount of activity among those who are currently active. Thus, health enhancing physical activity (HEPA) can, in addition to, and instead of, structured and planned exercise and sports also comprise of other forms of physical activity, such as commuting or running errands on foot or by bicycle and physically demanding leisuretime hobbies.

Several different surveys conducted in many European countries, and in North America and Australia show that in most modern industrialised countries only a minority of the adult population engage in regular weekly physical activity which meet the demands of the current recommendations of $\mathrm{HEPA}^{7-9}$. A survey recently conducted in 15 EU countries show great differences in the populations' activity levels between countries. However, in every country a substantial proportion of adults, and on average about 50 percent of the population in all EU countries, participate less than three hours in a typical week in various physical activities ${ }^{10}$. As a conclusion from the evidence of the health benefits of physical activity and the physical activity habits of ordinary people in industrialised modern countries, it can be stated that wide-range and long-term population strategies are needed for the promotion of HEPA

\section{Analysis of HEPA as a behaviour}

In the consensus statement on physical activity, fitness and health physical activity was defined as 'any bodily movement produced by the skeletal muscles that results in a substantial increase over the body energy expenditure' ${ }^{\prime}$. In the health and sports sciences HEPA can be understood and defined by its physiological characteristics, such as its intensity, duration and frequency, or by the type of activity, such as walking, cycling, swimming, soccer, badminton etc. For promotional purposes, however, it is important to understand the physical activity as behaviour with versatile psychological and contextual dimensions in addition to the physiological characteristics $^{11}$.

The domain of physical activity can be classified in five different main categories ${ }^{12}$. This on the basis of the social context and the psychological meaning of the behaviour, as well as the degree of free choice regarding the timing of the behaviour, and the resources and facilities needed or used while participating in the activity. The five domains are:

(1) occupational activities (e.g. physical activity at work),

(2) lifestyle activities (e.g. commuting or running errands on foot or by bicycle),

(3) recreational activities (e.g. hiking or dancing),

(4) fitness activities (e.g. jogging and swimming, walking for fitness), and

(5) sports activities (e.g. sports training and competition).

At an individual level, in principal, a person can get the recommended (almost) daily HEPA either by engaging in physical activity in one of the categories in most weekdays or by combining two or more types of activities during the course of the week. At population level, due to the differences in the prerequisites, life situations and priorities between individuals and groups, it is necessary to promote physical activity in each of the categories of HEPA in order to create realistic opportunities for different population groups and individuals.

\section{Need for a theoretically sound promotional framework}

The accumulated research data of the health benefits of physical activity have led to interventions intended to change the physical activity behaviour of individuals, groups or populations ${ }^{13}$. The analyses of the experiences have shown, however, that the use of randomised control trials to evaluate health promotion interventions is, in most cases, inappropriate, misleading and unnecessarily expensive, and therefore alternative approaches and multiple methods are needed ${ }^{14-16}$. The following conclusions, drawn from recent reviews of behavioural and intervention studies on physical activity, should be considered in order to successfully promote physical activity:

- Attention needs to be given to the identification and prioritisation of the determinants of HEPA, based on explicit theoretical models, such as social cognitive theory or the theory of planned behaviour ${ }^{16-19}$.

- Particular attention needs to be given to the environmental contexts, and the life conditions of population subgroups and the conditions connected with the phases of the life $\operatorname{span}^{16-18,20}$.

- The inherent process features of physical activity need to be understood, e.g. people in a population are in various stages of behaviour adoption, and the determinants for the initiation, short-term adherence and long-term maintenance of physical activity may be different ${ }^{18,21}$. One conceptualisation of the behaviour change process is provided through the idea of 
stages of behaviour change, introduced among others as a part of the transtheoretical theory by Prochasca and DiClemente 22-24 $^{24}$

- The domain of physical activity consists of different modes of behaviours ${ }^{12}$. At a given time a person can be in a very different stage of change in different modes of physical activity ${ }^{25}$. The determinants of various types of physical activities, as well as the probability of long-term maintenance of physical activity, in terms of moderate-intensity activity vs. high-intensity activity and program-centred vs. lifestyle integrated, are different ${ }^{11,18,21}$.

For promotional purposes the theoretical knowledge of the determinants of the target behaviour should be translated to a practical form. The PRECEDE-PROCEED model for health promotion planning combines the behaviour modification principles and the different determinants presenting them as Predisposing, Enabling and Reinforcing factors ${ }^{26}$.

The underlying pragmatic thinking is that when the favourable factors are simultaneously present, the likelihood of the behavioural change and adherence is increased. The observed determinants of physical activity from empirical studies ${ }^{18}$, can be reclassified into the categories of PRECEDE-PROCEED model (Table 1) ${ }^{27}$.

Most 'intraindividual' determinants, identified in the terms of attitude-behaviour models, are categorised as Predisposing factors. These include individual's attitudes, knowledge and outcome expectations. These can be influenced by using different forms of information delivery: mass media, education, teaching, training, counselling and guidance. Some external triggers or stimuli, such as sight of exercise facilities, may be considered either as Predisposing or Enabling factor. In principal, in order to improve the enabling factors, such as access to exercise facilities or availability of safe walking and cycling routes ${ }^{28}$, long term health policy and environmental planning is needed. However, sometimes it is possible to increase the use of available facilities, like the use of stairs instead of elevators, by simple external triggers $^{29}$.

Self-efficacy could be classified under the Predisposing or Enabling factors. Traditionally it refers to the person's perception of his capability to engage in physical activity despite interfering circumstances (rainy weather, being busy etc.) or the persons physical characteristics (health status, performance capacity). Sometimes an instructor or a health professional can influence self-perceptions by giving adequate advice or counselling on the equipment, type of activity or on coping, but self-perception can also be determined by the true opportunities in the person's environment.

On the basis of available empirical studies, the Predisposing, Enabling and Reinforcing factors are all relevant and important for the adoption and maintenance
Table 1 Summary of the determinants of physical activity from 33 studies (1988-91), based on Dishman and Sallis (1994) ${ }^{18}$, and reworked to fit the Preceed-Proceed model's categories (Green and Kreuter 1991$)^{25}$ of health behavior determinants, and the estimated importance of the determinants in terms of degree of association with physical activity (Laitakari and Miilunpalo 1998) ${ }^{26}$

\begin{tabular}{llc}
\hline $\begin{array}{l}\text { Determinant } \\
\text { category }\end{array}$ & \multicolumn{1}{c}{ Determinant description } & $\begin{array}{c}\text { Degree of } \\
\text { association }\end{array}$ \\
\hline $\begin{array}{l}\text { Predisposing } \\
\text { factors }\end{array}$ & Attitudes & + \\
& $\begin{array}{l}\text { Expected health and other } \\
\text { benefits }\end{array}$ & + \\
& Intention to exercise & ++ \\
& Self-motivation & ++ \\
& Self-schemata for activity & + \\
& Past program participation & ++ \\
& High risk for heart disease & ++ \\
Enabling factors & Perceived effort & - \\
& Income/socio-economic status & ++ \\
& Barriers to exercise & -- \\
& Lack of time & - \\
& Mood disturbance & -- \\
& Perceived health or fitness & ++ \\
& Self-efficacy for exercise & ++ \\
Reinforcing & Perceived access to facilities & + \\
factors & Social isolation & - \\
& Group cohesion & + \\
& Social support: spouse/family & ++ \\
\hline & Social support: staff/instructor & ++ \\
\hline
\end{tabular}

$++=$ repeatedly documented association with physical activity (either supervised or free-living).

$+=$ weak or mixed evidence of positive association.

$--=$ repeatedly documented negative association.

$-=$ weak or mixed evidence of negative association.

of physical activity. Referring to the above described conclusions about physical activity as a behaviour, the process features of physical activity and the diversity of the determinants, it is obvious that at population level any wide-range and long-lasting promotional results can not be achieved by single and simple acts. However, regular health-enhancing physical activity can effectively be promoted by combining different strategies and acting simultaneously in different settings and by different methods. Examples are building safe and appealing walking and cycling routes and economic and easily accessible exercise facilities, organising regular and versatile functions and appealing happenings in local sports clubs and residence areas, providing guided groups and guidance and supportive services for individuals, and delivering information and advertising.

In the end, promotional activities are needed where people live and work, i.e. at local level. At the moment theory and evidence based guidebooks for local level promotional activities are available ${ }^{30}$. These kind of local promotional activities can, however, be stimulated and supported by national programs ${ }^{31}$, and guidelines for health-enhancing physical activity programmes, based on the analysis of experiences in four European programmes, have recently been published ${ }^{32}$. 


\section{References}

1 Bouchard C, Shephard RJ, Stephens T, eds. Physical activity, fitness, and bealth. International proceedings and consensus statement. Champaign, IL: Human Kinetics, 1994.

2 U.S. Department of Health and Human Services. Physical Activity and Health: A Report of the Surgeon General. Atlanta, GA. U.S. Department of Health and Human Services, Centers for Disease Control and Prevention, National Center for Chronic Disease Prevention and Health Promotion, 1996.

3 Vuori I. Does physical activity enhance health? Patient Educ. Couns. 1998; 33: S95-S103.

4 Pate RR, Pratt M, Blair SN, et al. Physical activity and public health. A recommendation from the Centers for Disease Control and Prevention and the American College of Sports Medicine. JAMA 1995; 273: 402-7.

5 NIH Consensus Development Panel on Cardiovascular Health. Physical Activity and Cardiovascular Health. JAMA 1996; 276: 241-6.

6 American College of Sports Medicine. The Recommended Quantity and Quality of Exercise for Developing and Maintaining Cardiorespiratotory and Muscular Fitness, and Flexibility in Healthy Adults. Med. Sci. Sports Exerc. 1998; 39: 975-91.

7 Bauman A, Owen N, Rushworth R. Recent trends and sociodemographic determinants of exercise participation in Australia. Community Health Studies 1990; 14: 19-26.

8 Caspersen C, Merritt R, Stephens R. International Physical activity Patterns: a methodological perspective. In: Dishman RK, ed. Advances in Exercise Adberence. Champaign, IL: Human Kinetics Press, 1994: 73-110.

9 Oja P. Descriptive Epidemiology of Health-Related Physical Activity and Fitness. Res. Quarterly Exercise Sport 1995; 66: 303-12.

10 Institute of European Food Studies. A pan-EU survey on consumer attitudes to physical activity, body-weight and health. Luxembourg: Office for Official Publications of the European Communities, 1999.

11 Laitakari J, Vuori I, Oja P. Is long-term maintenance of healthrelated physical activity possible? Health. Educ. Res. 1996; 11: $463-77$.

12 Marttila J, Laitakari J, Nupponen R, Miilunpalo S, Paronen O. The versatile nature of physical activity - on the psychological, behavioural and contextual characteristics of healthrelated physical activity. Patient Educ. Couns. 1998; 33: S29S38.

13 Blair S, Morrow J (ed.) Theme Issue: Physical Activity Interventions. Am. J. Prev. Med. 1998; 15: 255-440.

14 World Health Organization. Health Promotion Evaluation: Recommendations to Policymakers. Copenhagen: WHO, 1988.

15 Epstein L. Integrating theoretical approaches to promote physical activity. In Blair S, Morrow J. (ed.) Theme Issue: Physical Activity Interventions. Am. J. Prev. Med. 1998; 15: $257-65$.
16 Godin G, Shephard RJ. Use of attitude-behaviour models in exercise promotion. Sports Medicine 1990; 10: 103-21.

17 Godin G. Social-cognitive models. In: Dishman RK, ed. Advances in exercise adberence. Champaign, IL: Human Kinetics, 1994: 113-136.

18 Dishman RK, Sallis JF. Determinants and interventions of physical activity and exercise. In: Bouchard C, Shepard RJ, Stephens T, eds. Physical activity, fitness, and bealth International proceedings and consensus statement. Champaign, IL: Human Kinetics Publishers, 1994: 214-238.

19 Godin G, Kok G. The theory of planned behavior: a review of its applications to health-related behaviors. Am. J. Health Prom. 1996; 11: 87-98.

20 Biddle SJH. Exercise psychology. Sport Science Review 1992; 1: 79-92.

21 Sallis JF, Hovell MF. Determinants of exercise behaviour Exercise and Sport Sciences Reviews, 18. Baltimore, MD Williams and Wilkins, 1990: 307-330.

22 Prochaska JO, DiClemente CC. Stages and processes of selfchange in smoking: toward an integrative model of change. J. Consulting Clin. Psychol. 1983; 51: 390-5.

23 Prochaska JO, Velicer WF, Rossi JS. Stages of change and decisional balance for 12 problem behaviors. Health Psychol. 1994; 13: 39-46.

24 Prochaska JO, Velicer WF. The transtheoretical model of health behavior change. Am. J. Health Prom. 1997; 12: 3848.

25 Miilunpalo S, Nupponen R, Laitakari J, Marttila J, Paronen O. Stages of change in two modes of health-enhancing physical activity: methodological aspects and promotional implications. Health Education Research 2000; 15: 435-48.

26 Green LW, Kreuter MW. Health Promotion Planning. An Educational and Environmental Approach. Mountain View, CA: Mayfield Publishing Company, 1991.

27 Laitakari J, Miilunpalo S. How can physical activity be changed - Basic concepts and general principles in the promotion of health-related physical activity. Patient Educ. Couns. 1998; 33: S47-S59.

28 Oja P, Vuori I, Paronen O. Daily walking and cycling to work: their utility as health-enhancing physical activity. Patient Educ. Couns. 1998; 33: S87-S94.

29 Blamey A, Mutrie N, Aitchison T. Health promotion by encouraged use of stairs. BMJ 1995; 311: 289-90.

30 U.S. Department of Health and Human Services. Promoting Physical Activity. A Guide for Community Action. Champaign, IL: Human Kinetics, 1999.

31 Vuori I, Paronen O, Oja P. How to develop local physical activity program with national support: the Finnish experience. Patient Educ. Couns. 1998; 33: S111-20.

32 Foster C. Guidelines for health-enhancing physical activity promotion programmes. The European Network for the Promotion of Health-Enhancing Physical Activity. UKK Institute for Health Promotion Research, Tampere, Finland 2000. 